\title{
Obesity: Care in Rural Communities
}

\author{
Debra K. Sapaugh \\ University of Missouri, Columbia, MO, USA \\ Email: cdsapaugh@yahoo.com
}

How to cite this paper: Sapaugh, D.K. (2018) Obesity: Care in Rural Communities. Open Access Library Journal, 5: e4595. https://doi.org/10.4236/oalib.1104595

Received: April 11, 2018

Accepted: May 28, 2018

Published: May 31, 2018

Copyright (c) 2018 by author and Open Access Library Inc.

This work is licensed under the Creative Commons Attribution International License (CC BY 4.0).

http://creativecommons.org/licenses/by/4.0/

\begin{abstract}
Adult obesity is a major health concern in the United States. Adults who are overweight or obese are at higher risk for chronic illnesses, which include hypertension, diabetes, and cardiovascular disease. In addition, obesity significantly contributes to increased healthcare costs. Rural adults experience higher rates of obesity as well as correspondingly elevated mortality and morbidity than their urban counterparts. The United States Preventative Task Force provides recommendations for addressing adult obesity. However, if these resources are not available in rural communities, nurse practitioners cannot follow these recommendations. A cross-sectional study was conducted with rural Missouri nurse practitioners. Findings showed although nurse practitioners feel obesity has a negative impact on the health of their patients, resources are limited to address obesity in their population.
\end{abstract}

\section{Subject Areas}

Nursing, Public Health

\section{Keywords}

Obesity, Diabetes Mellitus, Coronary Artery Disease, PVD, PAD, CVA, Chronic Illness

\section{Introduction}

Obesity is rising and has become a major causative factor of chronic illnesses: (hypertension (HTN), dyslipidemia, type 2 diabetes (T2D), coronary heart disease, various respiratory problems, cardiovascular (CVD) and peripheral vascular disease (PVD), cerebral vascular accidents (CVA), as well as certain types of cancer) [1] [2]. Chronic illnesses and associated lost wages, especially in those younger than 65 years [3] [4] behoove researchers to evaluate utilization of existing resources as well as their availability. If treatment of obesity is not addressed, obesity and obesity-related illnesses will impact our future global health and economy in enormous proportions [5]. 


\section{Background and Significance}

Obesity is defined as one who has a BMI of 30 or greater [3]. Since 1980, the rate of obesity in the United States has doubled [6], which affects our population without proclivity to age, education, socioeconomic status (SES), gender, or race [2]. Obesity predisposes our population to chronic illnesses and many obese patients have more than one chronic illness [1]. High body weights reduce quality of life and increase mortality rates [1] [4]. Obesity and corresponding co-morbidity rates are higher in rural regions in comparison to urban areas [7]. Annual obesity-related deaths were 112,000 and direct-related medical expenditures were 152 billion dollars in 2009 alone [8].

Obesity negatively affects workplace productivity. Employers incur elevated healthcare costs, higher absenteeism, and lower productivity associated with hiring obese individuals [9] [10]. The 2010 U. S. healthcare reform act allows employers to charge obese individuals $30 \%$ - 50\% more for health insurance if they decline to participate in weight-reduction programs [10]. Unhealthy weight causes an increase of sick days: 6 more sick days for men/annum and each year obese women take 9.4 more duvet days than their healthy counterparts. Obesity-related absenteeism costs employers approximately $\$ 6.4$ billion per year. As a result of lost productivity, wages may be reduced and when attempting to find alternative employment, obese individuals are less likely to be employed and/or promoted than their healthy peers [10].

Obesity and its related physical impairments significantly influence quality of life [11] and significantly correlate with depression [12]. Regardless of education and income levels, obese individuals are viewed as lazy, unkempt, and inferior to those of normal weight [13] [14]. These negative perceptions discourage obese individuals from being outdoors and being physically active [15].

In the clinic setting, patients are weighed, their vital signs obtained, and their concerns addressed, however professionals need to address obesity as an underlying cause of chronic illness [16]. The Hastings Center [17] reported that of those surveyed, $88 \%(n=227)$ were unhappy with their weight status. However, patients who receive advice from their practitioners are more likely to follow recommendations for diet and exercise [15]. Therefore, guidelines should be reviewed with the goal of improving community health. Guidelines would support practitioners with their endeavor to address patient's weight concerns and support patients' progress toward weight loss goals.

\section{Statement of Purpose}

Guidelines are available to direct health care professionals to promote healthy lifestyles. The purpose of this study was to describe how rural health care providers perceive obesity in their communities. A one-time online survey of Missouri Family Nurse Practitioners was utilized to evaluate Nurse Practitioner (NP) perceptions of obesity-related chronic illness, current training and resources, as well as treatment availability to address obesity. 


\section{Review of the Literature}

A search was performed utilizing the PubMed database with $\mathrm{MeSH}$ headings, CINAHL, Medline, and Scopus databases. Search limits included publication dates of 2010-2014, English language, human species, and articles linked to full text. The search of PubMed with MeSH and general terms included obesity, abdominal and perception. The general terms used were obesity, attitudes or perception, and community. To further delineate aspects of rural obesity, the search of CINAHL included these terms: rural health personnel, services, and rural populations. The search of CINAHL and Scopus was limited to studies performed in the United States and further restricted to studies with available abstracts. Articles including adult participants, adult attitudes or perceptions of obesity, as well as community perceptions and rural health resources were included. Restricted articles included those addressing maternal issues, childhood obesity, and those primarily addressing chronic diseases or illnesses (Table 1).

\subsection{Evaluation of Literature Findings}

Boo [18] found weight misperception was manifested both in males and females. Men tend to underestimate and women tend to overestimate their weight [18] [19]. Underestimation of one's weight affects how a person views their family's weight and thus, promotes familial obesity [18]. However, the trend toward weight gain may reduce current perceptions of need for weight loss solutions [20]. People who underestimate their body weight are less likely to perceive the need for weight loss solutions, while those who overestimate their weight tend to be more prone to fad dieting due to unnecessary weight concerns [18] [21]. Active overweight individuals considered themselves "generally healthy" and do not perceive health risks associated with being overweight and obese [20].

\subsection{Behavioral Aspects}

Cognitive, effective, and behavioral components are all aspects of body image. Obesity has been associated with poor self-esteem, which alters psychological and psychosocial aspects leading to further unhealthy behaviors such as Internet searches for weight loss solutions [22]. Internet searches with obesity and weight loss solutions are considerably high (78\% and 75\% respectively). Increased Internet searches corresponded with weight: the more the participant weighed, the more they searched the Internet for weight loss solutions and obese individuals overwhelmingly acted upon advice found on various dietary websites [21] (Table 1).

Self-perception of weight status plays an important role in health-seeking behavior. If a patient misperceives their weight, they were less likely to nurture healthy-weight behaviors [18]. Self-misperception of weight status can also promote unhealthy behaviors. With rising prevalence of obesity, individual perceptions have changed suggesting normalization. Therefore, perceptions of risk factors associated with obesity as well as the urgency to seek weight-reduction interventions have been minimized [20]. 
Table 1 .

\begin{tabular}{|c|c|c|c|c|c|}
\hline DATABASE & SEARCH Years & SEARCH TERMS & $\begin{array}{l}\text { \# of Articles } \\
\text { Identified }\end{array}$ & $\begin{array}{l}\text { \# of Articles } \\
\text { Included }\end{array}$ & $\begin{array}{l}\text { \# of Articles } \\
\text { Excluded }\end{array}$ \\
\hline CINAHL & $2010-2014$ & $\begin{array}{c}\text { Attitude of ObesitycAND } \\
\text { Attitudes AND community } \\
\text { Limited to: English Language, } \\
\text { Linked to Full Text }\end{array}$ & 43 & 5 & 38 \\
\hline $\begin{array}{l}\text { MEDLINE } \\
\text { (OVID) }\end{array}$ & $2010-2014$ & $\begin{array}{c}\text { Attitude AND Obesity AND } \\
\text { Community. Limited to: Review } \\
\text { Articles, Full Text, Human Subjects } \\
\text { English Language, all adults (19+ years) }\end{array}$ & 153 & 0 & 153 \\
\hline PubMed & $2009-2014$ & $\begin{array}{l}\text { “Obesity, Abdominal” [Mesh] AND } \\
\text { "Perception” [Mesh } \text { AND (“2009/0715” } \\
\text { [PDat]: "2014/07/13’ [PDat\}) }\end{array}$ & 6 & 0 & 6 \\
\hline Scopus & $2010-2014$ & $\begin{array}{l}\text { Obesity AND Adult AND attitude OR } \\
\text { Perception. Limits included: Obesity, } \\
\text { United States, Human, Humans, and the } \\
\text { English Language }\end{array}$ & 58 & 7 & 51 \\
\hline CINAHL & $2010-2015$ & $\begin{array}{l}\text { (MH "Rural Health Personnel") OR } \\
\text { (MH "Rural health Centers") OR (MH } \\
\text { "Rural Health") PR (MH "Rural Population") } \\
\text { OR "rural health OR (rural population and } \\
\text { Health) AND obesity in adults in the United } \\
\text { States" (AND) Obesity Limiters-Age Groups: } \\
\text { All Adult; Journal Subset: Peer Reviewed; } \\
\text { Peer Reviewed; English Language }\end{array}$ & 136 & 11 & 125 \\
\hline
\end{tabular}

Dietary behaviors of rural habitants also influence weight status. One potential cause of rural obesity is widespread availability of low cost, high-density foods. Further, lack of access to and associated costs of healthy foods is another disadvantage of rural communities [23] [24]. Additionally, poor rural health outcomes have been associated with high levels of uninsured residents, low educational attainment, high unemployment rates, and low treatment compliance [25].

\subsection{Cultural Influences}

Cultural influences and individual beliefs and attitudes toward overweight and obesity cannot be overlooked. In a study by Latner, Knight, and Illingworth [26] Pacific Islanders and African Americans (AA) were found to have higher BMIs along with corresponding positive body images [26] [27]. Obese AA were less likely to classify themselves as such and had higher self-perceptions [19] while White women (WW) correlated being overweight with negative characteristics and focused on social as well as emotional consequences of larger body sizes [27].

\subsection{Role of Rural Health Departments}

Rural health departments serve large rural areas. Large portions of rural residents are impoverished and greater than one-half is of nonwhite decent. Rural health centers are often overburdened with primary and preventative services 
due to necessary services for large portion of migrant and seasonal workers. However, even though local health departments serve large numbers of residents, these residents report poor to fair health and are twice as likely to report physical limitations [28]. Further, as rural health centers are dependent on government funding, many services such as weight reduction programs may not be offered.

\subsection{Rural Resources}

Complications of access to healthcare prevent rural citizens from seeking health-promoting services such as referrals to nutritionists and physical activity training [25] [29]. In addition, due to low SES, preventative care, obesity treatment, and diet and physical activity coordinators are inaccessible. High levels of unemployment and low SES further prohibit travel, which may be necessary to access valuable services. Further, lack of public transportation, low recreational opportunities, and lack of indoor facilities during extreme weather conditions promote obesity in rural areas [24] [25].

\subsection{Implications for Private Practice}

If body weight is misperceived, it is unlikely obese individuals will seek weight loss solutions [18]. Existing perceptions and beliefs can be used to increase public awareness of healthy weights and help curb the ongoing obesity epidemic [18]. Those who underestimate their weight status can be educated about healthy weights and, therefore, weight loss can be promoted [18]. Further, Lewis et al. [21] suggested government and community organizations should provide services that would promote weight loss initiatives.

The FDA [30] considers a five percent weight reduction to be clinically significant. Weight loss with coinciding behavioral interventions decreased the incidence of DM by $50 \%$ over two-three years. Weight loss results in immediate reductions in blood pressure, waist circumference, and glucose tolerance [30]. Further, interventions that combined lifestyle changes and behavioral interventions with pharmacologic agents (orlistat/metformin) resulted in greater weight loss and improved physiologic outcomes [4].

The U. S. Preventative Services Task Force [4] makes certain recommendations for specific obesity-related clinical interventions. Currently, the USPSTF [4] recommends screening all adults for obesity. Clinicians should refer obese patients to intensive, multi-component behavioral interventions. Multi-level behavioral components include group, individual, and physical activity sessions, setting weight loss goals, improving diet or nutrition, addressing barriers to change, active use of self-monitoring, and promote patient-centered strategic methods to maintain lifestyle changes [4].

\section{Methods and Procedures}

\subsection{Design}

This study utilized a descriptive design to explore rural Nurse Practitioner per- 
ceptions of obesity, resources in rural ("all population, housing, and territory not included in an urban area" [31] areas, and barriers Missouri NPs face when addressing obesity in their patient populations.

\subsection{Method of Data Collection}

Data was collected via a one-time online survey (Table 2, Table 3). After thorough evaluation of the literature, no survey tool was found fit for this study. The principal investigator developed a survey for this study based on findings of the Hospital Association of San Diego and Imperial Counties [32] and Forman-Hoffman, Little, and Wahls [33]. These surveys evaluated practitioners' barriers of obesity treatment to include their perception of obesity and overall health, adequate training to address obesity, as well as the availability of weight management services within their geographical location [32] [24].

\subsection{Setting}

This study provided online access to the survey. NPs were able to utilize individual time and desired setting to complete surveys. No compensation was offered as a result of participation.

\subsection{Participation/Population Demographics}

Participation was based on rural Nurse Practitioners who were members of the Missouri Nurses Association (MONA) and were willing to submit online surveys. Demographic data was collected from survey responses to questions regarding age, number of years practiced, and gender of participants as well as how many miles from a regional medical center and size of population served (Table 2).

Table 2. Budget analysis.

\begin{tabular}{lc}
\hline Anticipated costs of project & $\$ 300.00$ \\
Travel and lodging expenses & $\$ 5000.00$ \\
Computer and electronic access & $\$ 7000.00$ \\
Office and office equipment & $\$ 300.00$ \\
Survey tools & $\$ 300.00$ \\
Access/application for MONA listserve & $\$ 200.00$ \\
Utilities & $\$ 250.00$ \\
Total Cost & $\$ 13,050$ \\
Contributions & \\
Utilize student computer/electronic access & $\$ 5000.00$ \\
Utilize student home office/equipment & $\$ 7000.00$ \\
Survey tools/Student access/Qualtrics & $\$ 300.00$ \\
Student home office/utilities & $\$ 250.00$ \\
MONA to send out survey link & $\$ 200.00$ \\
Total of contribution & $\$ 12,750$ \\
Cost to surveyor & $\$ 300.00$ \\
\hline
\end{tabular}


Table 3. Demographic data.

\begin{tabular}{ccccc}
\hline $\begin{array}{c}\text { Number of years } \\
\text { practiced in a rural }\end{array}$ & $1-5$ years & $5-10$ years & $10-15$ years & $>15$ years \\
setting: N $=48$ & $14.58 \%$ & $25 \%$ & $20.83 \%$ & $39.58 \%$ \\
\hline Age of NP: N $=49$ & $25-35$ & $36-40$ & $41-45$ & $>45$ years \\
& $1.88 \%$ & $10.2 \%$ & $10.2 \%$ & $75.51 \%$ \\
Gender of NP: $\mathrm{N}=49$ & Male & Female & & \\
& $8.16 \%$ & 91.84 & N/A & N/A \\
Size of NPs & $<5000$ & $5001-10,000$ & $10,001-15,000$ & $>15,000$ \\
population: $\mathrm{N}=46$ & $28.57 \%$ & $26.09 \%$ & $13.04 \%$ & $28.57 \%$ \\
How many miles to a & $<15$ miles & $15-25$ miles & $26-35$ miles & $>35$ miles \\
Regional Medical & $55.1 \%$ & $20.41 \%$ & $8.16 \%$ & $16.33 \%$ \\
Center: $\mathrm{N}=49$ & & & & \\
\hline
\end{tabular}

\subsection{Sampling (Inclusion/Exclusion) Criteria}

NP MONA members currently practicing or those who have practiced in rural settings in the past five years met inclusion. Urban NPs and NPs who were not members of MONA were excluded.

\subsection{Barriers to Implementation}

Limitations included low numbers of returned surveys and ability to initiate and distribute the survey by the proposed date.

\subsection{Data Collection Plan}

Data collection included participant demographics, perception of obese population, overall health, obesity-related chronic illness and time-allotment, referral services, readiness for change, weight loss strategies, and skepticism related to weight-loss modalities.

\subsection{Data Analysis}

Survey data was evaluated utilizing SPSS and descriptive analysis to identify means and frequencies.

\subsection{Ethical Considerations with Potential Risks and Benefits to Subjects}

There were no perceived risks to participants. Data was collected without identifiers, responses were anonymous, and participation conveyed consent. Potential benefits included description of NP perceptions of rural resources.

\subsection{Timeline}

The survey was distributed to NP members of MONA on January 05, 2016. Due to no new responses for 12 days, the survey was closed on January 25, 2016 at 6:45 PM.

\subsection{Resources Needed and Estimate Resource Costs}

Estimated costs were minimal (Table 3 ) and the primary researcher's responsibility. 


\subsection{Approvals for Implementation}

Access to MONA listserv was granted and IRB approval was received from the University of Missouri

\subsection{Evaluation}

Forty-nine surveys were received (MONA did not release the quantity of inquiries sent). Data regarding size of practice population was missing from three surveys. Data regarding years of practice, referral services, and weight loss strategies were missing from one survey.

\subsection{Analysis of Demographics}

Most NPs (40\%) had been practicing in the rural setting for over 15 years, 21\% had 10 - 15 years of practice, $25 \%$ had 5 - 10, and $15 \%$ had $1-5$ years of practice. Seventy-six percent were over the age of $45,5 \%$ were between $41-45,5 \%$ were 36 - 40, and $4 \%$ were 25 - 35 years of age. Thirty percent of respondents served populations of less than 5000 residents, $12 \%$ served populations of $5001-10,000$, $13 \%$ served populations of $10,001-15,000$, and $30 \%$ served more than 15,000 residents. Fifty-five percent served patients residing less than 15 miles from a regional medical center, $20 \%$ were 15 - 25 miles, eight percent were 26 - 35 miles, and $16 \%$ were more than 35 miles from a regional medical center (Table 3).

\subsection{Analysis of Survey Questions}

The majority (96\%) of respondents either agreed (33\%) or strongly agreed (63\%) that large portions of their populations are affected by obesity. In addition, the majority (96\%) of participants either agreed or strongly agreed that obesity was an overall indicator of health. Over half (76\%) of respondents agreed or strongly agreed that chronic illnesses associated with obesity dominated the majority of office visits, therefore there was not enough time for weight reduction counseling. Over half (60\%) of participants agreed or strongly agreed no weight-reduction referral services were available in their communities. In addition, the majority (71\%) agreed or strongly agreed their populations showed lack of interest and/or readiness for change. Once again, the majority (70\%) of respondents either agreed or strongly agreed there is inadequate training to promote effective weight loss strategies. Finally, almost all respondents (92\%) agreed or strongly agreed that ineffective strategies lead to skepticism of obesity counseling and/or proposed treatments (Table 4).

\section{Implications and Conclusions}

This study revealed information consistent with statistics regarding NPs. The majority (68\%) of Missouri's APRNs were at least 40 years of age [34] and the national average age for NPs was 49 years. Most NPs have practiced for an average of 10 years and $20 \%$ practice in rural settings [35]. Further, women 
Table 4. Nurse practitioner perceptions.

\begin{tabular}{|c|c|c|c|c|}
\hline Questions & Strongly & Agree & Agree Disagree & Strongly Disagree \\
\hline $\begin{array}{l}\text { Large portions of } \\
\text { the population I serve } \\
\text { are affected by obesity. } \\
\mathrm{N}=49\end{array}$ & $63.27 \%$ & $32.65 \%$ & $4.08 \%$ & $0 \%$ \\
\hline $\begin{array}{l}\text { Obesity is an indicator } \\
\text { of overall health for the } \\
\text { population I serve. } \mathrm{N}=49\end{array}$ & $53.06 \%$ & $42.86 \%$ & $2.04 \%$ & $2.04 \%$ \\
\hline $\begin{array}{l}\text { More serious chronic illnesses } \\
\text { associated with obesity take up } \\
\text { the majority of an office visit } \\
\text { (Not enough time for obesity/ } \\
\text { weight-reduction counseling. } \\
\mathrm{N}=49\end{array}$ & $30.61 \%$ & $44.9 \%$ & $22.46 \%$ & $2.04 \%$ \\
\hline $\begin{array}{l}\text { The community in which I serve } \\
\text { does not offer weight-reduction } \\
\text { referral services. } \mathrm{N}=48\end{array}$ & $27.08 \%$ & $33.33 \%$ & $22.92 \%$ & $16.67 \%$ \\
\hline $\begin{array}{l}\text { The population I serve shows } \\
\text { a lack of interest and/or } \\
\text { readiness for change. } \mathrm{N}=49\end{array}$ & $20.41 \%$ & $51.02 \%$ & $22.45 \%$ & $6.12 \%$ \\
\hline $\begin{array}{l}\text { In the community I serve, } \\
\text { I feel there is inadequate } \\
\text { training to promote effective } \\
\text { weight loss strategies. } \mathrm{N}=49\end{array}$ & $29.17 \%$ & $50 \%$ & $16.67 \%$ & $4.17 \%$ \\
\hline $\begin{array}{l}\text { Ineffective strategies can lead } \\
\text { to skepticism of obesity } \\
\text { counseling and proposed } \\
\text { treatments. } \mathrm{N}=49\end{array}$ & $36.73 \%$ & $55.1 \%$ & $6.12 \%$ & $2.04 \%$ \\
\hline
\end{tabular}

constitute the majority of practicing NPs [36]. As NPs are starting to fill the gap left by primary care physicians in most of Missouri counties [34], it is important to evaluate NPs perceptions of rural resources for obesity treatment.

Obesity has been identified as a major underlying factor of many chronic illnesses [5]. Rural communities have higher obesity rates and associated chronic illnesses as compared to urban areas [7]. This study indicated the majority of clinician time was spent addressing chronic illnesses thus little time was left for weight loss counseling. Literature suggested obese patients should be referred for intense, multi-component behavioral therapy [4], however this study revealed the majority of Missouri's NPs perceived a lack of available resources for obesity treatment.

This study found NPs felt inadequately trained to promote effective weight loss strategies. Further, at least half of respondents identified lack of interest and/or resistance to change. Complicated by fad dieting and other ineffective weight-loss strategies, weight-loss counseling has been met with skepticism. If health care providers are to successfully address the current obesity epidemic, supplemental training and resources need to be allocated to rural communities.

Rural health centers may be unable to incorporate weight-loss strategies into their already overburdened, underfunded systems. Due to lack of transportation, high levels of poverty, and high unemployment rates rural citizens continue to 
be vulnerable and underserved [25] [29]. NPs perceived that obesity affects the health of their rural populations. Further, there is misperception about obesity and there is a need to educate rural communities about the benefits of weight loss. Moreover, patient-centered caring, and availability of affordable healthy foods would have high likelihood of promoting weight loss treatment compliance [4].

Rural health: Where resources are few and disparities are many. Simply reducing body weight by five percent could reduce mortality rates [30]. Nonetheless, without imperative resources, obesity rates will continue to rise. Rural healthcare providers must find and promote innovative initiatives to address obesity.

\section{References}

[1] National Heart, Lung, and Blood Institute (n.d.) Clinical Guidelines on Identification, Evaluation, and Treatment of Overweight and Obese Adults. http://www.nhlbi.nih.gov/guidelines/obesity/ob_home.htm

[2] Centers for Disease Control and Prevention (2014) Adult Obesity Facts. http://www.cdc.gov/obesity/data/adult.html

[3] Centers for Disease Control and Prevention (2012) Defining Overweight and Obesity. http:/www.cdc.gov/obesity/adult/defining.html

[4] United States Preventive Services Task Force (2012) Final Recommendation Statement: Obesity in Adults: Screening and Management. http://www.uspreventiveservicestaskforce.org/Page/Document/RecommendationSt atementFinal/obesity-in-adults-screening-and-management

[5] Centers for Disease Control and Prevention (2012) Overweight and Obesity: Causes and Consequences. http://www.cdc.gov/obesity/adult/causes/index.html

[6] Harvard School of Public Health [HSPH] (2014) Obesity Has Doubled since 1980, Major Global Analysis of Risk Factors Reveals. https://www.hsph.harvard.edu/news/press-releases/worldwide-obesity/

[7] Brewer, K.H. and Langerman, H. (2013) Promising Practices to Prevent and Address Obesity in Rural Communities. Rural Health Brief, 4, 1-6. http://www.norc.org/PDFs/Obesity\%20Brief-Jun2013_YSeries_Single\%20Pages.pdf

[8] Forbes (2014) The Business of Obesity and What It Costs Us. http://www.forbes.com/sites/bethhoffman/2013/03/22/the-business-of-obesity/

[9] Brown, A. and McGeeney, K. (2013) For U. S. Workers, Lack of Exercise Most Linked to Obesity.

http://www.gallup.com/poll/162359/workers-lack-exercise-linked-obesity.aspx

[10] Begley, S. (2012) As America's Waistline Expands, Costs Soar. http://www.reuters.com/article/2012/04/30/us-obesity-idUSBRE83T0C820120430

[11] Kolotkin, R.L., Meter, K. and Williams, G.R. (2001) Quality of Life and Obesity. Obesity Review, 2, 219-229. https://doi.org/10.1046/j.1467-789X.2001.00040.x

[12] Luppino, F.S., de Witt, L.M., Bouvy, P.F., Stijnen, T., Culipers, P., Pennix, B.W. and Zitman, F.G. (2010) Overweight, Obesity, and Depression: A Systematic Review and Meta-Analysis of Longitudinal Studies. Archives of General Psychiatry, 67, 220-229. https://doi.org/10.1001/archgenpsychiatry.2010.2

[13] Hansson, L.M. and Rasmussen, F. (2014) Attitudes towards Obesity in the Swedish 
General Population: The Role of One's Own Body Size, Weight Satisfaction, and Controllability Beliefs about Obesity. Body Image, 11, 43-50. https://doi.org/10.1016/j.bodyim.2013.10.004

[14] Ambwani, S., Thomas, K.M., Hopwood, C.J., Moss, S.A. and Grilo, C.M. (2014) Obesity Stigmatization as the Status Quo: Structural Considerations and Prevalence among Young Adults in the U. S. Eating Behaviors, 15, 336-370.

https://doi.org/10.1016/j.eatbeh.2014.04.005

[15] Krueter, M.W., Chheda, S.G. and Bull, F.C. (2000) How Does Physician Advice Influence Patient Behavior? Evidence for a Priming Effect. Archives of Family Medicine, 9, 426-433. https://doi.org/10.1001/archfami.9.5.426

[16] Vine, M., Hargeaves, M.B., Briefel, R.R. and Orfield, C. (2013) Expanding the Role of Primary Care in the Prevention and Treatment of Childhood Obesity: A Review of Clinic- and Community-Based Recommendations and Interventions. Journal of Obesity, 2013, Article ID: 172035. https://doi.org/10.1155/2013/172035 http://www.hindawi.com/journals/jobe/2013/172035/

[17] Hastings Center (2013) If Shaming Reduced Obesity, There Would Be No Fat People. http://www.dishlab.org/pubs/Tomiyama\%20Mann\%202013\%20If\%20shaming\%20r educed\%20obesity,\%20there\%20would\%20be\%20no\%20fat\%20people.pdf

[18] Boo, S. (2014) Misperception of Body Weight and Associated Factors. Nursing \& Health Sciences, 16, 468-475. https://doi.org/10.1111/nhs.12154

[19] Fletcher, J.M. (2014) The Interplay between Gender, Race and Weight Status: Self Perceptions and Social Consequences. Economics \& Human Biology, 14, 79-91. https://doi.org/10.1016/j.ehb.2012.03.003

[20] Ely, G.E., Miller, K. and Dignan, M. (2010) The Disconnect between Perceptions of Health and Measures of Health in a Rural Appalachian Sample: Implications for Public Health Social Workers. Social Work in Health Care, 50, 292-304. https://doi.org/10.1080/00981389.2010.534342

[21] Lewis, S., Thomas, S.L., Warwick Blood, R., Castle, D., Hyde, J. and Komersaroff, P.A. (2010) "I'm Searching for Solutions": Why Are Obese Individuals Turning to the Internet for Help and Support with "Being Fat"? Health Expectations, 14, 339-350. https://doi.org/10.1111/j.1369-7625.2010.00644.x

[22] Koff, E., Benavage, A. and Wong, B. (2001) Body Image Attitudes and Psychosocial Functioning in Euro-American and Asian-American College Women. Psychological Reports, 88, 917-928. https://doi.org/10.2466/pr0.2001.88.3.917

[23] Casey, A.A., Elliott, M., Glanz, K., Haire-Joshu, D., Lovegreen, S.L., Saelens, B.E., Brownson, R.C., et al. (2008) Impact of the Food Environment and Physical Activity Environment on Behaviors and Weight Status in Rural U. S. Communities. Preventive Medicine, 47, 600-604. https://doi.org/10.1016/j.ypmed.2008.10.001

[24] Chen, Y., Rennie, D.C. and Dosman, J.A. (2009) Changing Prevalence of Obesity in a Rural Community between 1977 and 2003: A Multiple Cross-Sectional Study. Public Health, 123, 15-19. https://doi.org/10.1016/j.puhe.2008.06.006

[25] Jackson, J.E., Doescher, M.P., Jereant, A. and Hart, L.G. (2005) A National Study of Obesity Prevalence and Trends by Type of Rural County. Journal of Rural Health, 21, 140-148. https://doi.org/10.1111/j.1748-0361.2005.tb00074.x

[26] Latner, J.D., Knight, T. and Illingworth (2011) Body Image and Self-Esteem among Asian, Pacific Islander, and White College Students in Hawaii and Australia. Eating Disorders, 19, 355-368. https://doi.org/10.1080/10640266.2011.584813

[27] Shoneye, C., Johnson, F., Steptoe, A. and Wardle, J. (2011) A Qualitative Analysis of 
Black and White British Women's Attitudes to Weight and Weight Control. Journal of Human Nutrition and Dietetics, 24, 536-542.

https://doi.org/10.1111/j.1365-277X.2011.01198.x

[28] Regan, J., Schempf, A.H., Yoon, J. and Politzer, R.M. (2003) The Role of Federally Funded Health Centers in Serving the Rural Population. Rural Health Policy, 19, 117-124. https://doi.org/10.1111/j.1748-0361.2003.tb00552.x

[29] Baird, A.G. and Wright, N. (2006) Poor Access to Care: Rural Health Deprivation? The British Journal of General Practice, 56, 567-568.

[30] Food and Drug Administration (2007) Guidance for Industry: Developing Products for Weight Management. http://www.fda.gov/downloads/Drugs/Guidances/ucm071612.pdf

[31] Health Resources and Services Administration (n.d.) Defining the Rural Population. http://www.hrsa.gov/ruralhealth/policy/definition_of_rural.html

[32] Hospital Association of San Diego and Imperial Counties (2013) 2013 Community Health Needs Assessment: Executive Summary. http://www.hasdic.org/documents/CHNASummary.pdr\#page $=92$

[33] Forman-Hoffman, V., Little, A. and Wahls, T. (2006) Barriers to Obesity Management: A Pilot Study of Primary Care Clinicians. Biomed Central Family Practice, 7, 35. https://doi.org/10.1186/1471-2296-7-35

[34] Missouri Department of Health and Senior Services (2014) Missouri's Nursing Workforce 2014.

http://health.mo.gov/living/families/primarycare/pdf/MissouriNursingWorkforce.p df

[35] American Academy of Nurse Practitioners (2015) NP Fact Sheet. https://www.aanp.org/all-about-nps/np-fact-sheet

[36] Cawley, J.F. (2012) Demographic Contrasts between NPs \& Pas. http://nurse-practitioners-and-physician-assistants.advanceweb.com/Archives/Artic le-Archives/Demographic-contrasts-between-NPs-PAs.aspx 